\title{
Modified Equivalent Load Method for Welding Distortion Analysis
}

\author{
Jaemin Lee ${ }^{1 /(1)}$ and Hyun Chung ${ }^{2, *(1)}$ \\ 1 Department of Naval Architecture and Ocean Engineering, Chonnam National University, 59626 Yeosu, \\ Jeonnam, Korea; jae27v@jnu.ac.kr \\ 2 Department of Naval Architecture and Ocean Engineering, Chungnam National University, \\ 34134 Daejeon, Korea \\ * Correspondence: hchung@cnu.ac.kr
}

Received: 26 September 2020; Accepted: 10 October 2020; Published: 13 October 2020

\begin{abstract}
In this study, modified equivalent load method for welding distortion analysis is suggested to improve its accuracy. To avoid the excessive computational time for welding distortion analysis of large welded structures, shell element-based elastic analysis methods are widely used, applying the inherent deformation approach. Equivalent nodal forces are commonly used in common FE (Finite Element) codes to enter these inherent deformation values. However, the conventional method cannot estimate precise longitudinal bending following the conventional equation. In this study, the problem of the existing equivalent load method is analyzed by a case study, and the modified equivalent load method that can estimate angular distortion, transverse shrinkage, and longitudinal bending is presented based on the FEM principle. The results show that by applying the proposed method, the shell element-based elastic FE approach for the welding distortion analysis can be achieved with improved accuracy.
\end{abstract}

Keywords: welding distortion analysis; simulation; ship production; equivalent load method

\section{Introduction}

Welding distortion in large welded structures is a significant problem affecting many industries worldwide. Large welded structures are composed of many subassemblies and parts that use various types of joints. If welding distortions can be predicted in the design stage through computational analysis, it is possible to mitigate them. However, it is time-consuming to simulate the thermomechanical welding process owing to the complex interactions among the metallurgical, mechanical, thermal, and fluid flows of the weld pool [1-3]. To accurately reflect all these effects, the welding analysis may require several hours, even for small specimens. This approach is physically unfeasible for large welded structures. As the results of the analysis are used for quality control, computational analyses of large-scale welded structures should be performed quickly [4].

Elastic finite element (FE) analysis using the shell element model is an efficient approach to simulate welding to predict distortions in large welded structures owing to its high computational efficiency [5]. There are two representative methods to predict large welded structures by elastic FE analysis using shell element model; inherent strain method and equivalent load method. Inherent strain method using the elastic FE analysis with shell elements to predict welding distortions and residual stress is feasible when the inherent strain value in the inherent strain zone is known [6]. An inherent strain is the permanent deformation in the inherent strain zone $[7,8]$. The inherent strain method has the advantage that both deformation and residual stress can be predicted at the same time. However, since most of the common FE codes do not support direct loading of strain, it is hard to follow the analysis procedure of the inherent strain method in the common FE codes. Meanwhile, 
the equivalent load method $[9,10]$ is an experimental method that directly uses distortion data, which is the inherent deformation from the test specimen. Mainly, four inherent deformations are measured; angular deformation, longitudinal deformation, longitudinal bending and transverse deformation. It calculates the equivalent nodal force and moments from the measured distortion data. These values can directly enter the common FE code as an equivalent nodal load vector that generates the inherent deformation. Equivalent load method directly uses the distortion data so it does not need long computational time for the input variables extraction [11-13]. However, the conventional equivalent load method equation cannot precisely predict the longitudinal bending distortion. In large welded structures, it is difficult to ignore the effect of longitudinal bending distortion $[14,15]$. If the conventional equivalent load method cannot precisely predict the longitudinal bending distortion, predicted accuracy of the analysis can be low when it is applied to the multi-welded structures such as large welded structures. Furthermore, considering that the allowable tolerance and quality standards for alignment of hull structural parts are very high [16], improving the accuracy of the conventional equivalent load method is requisite.

In this study, the problem of the existing equivalent load method is analyzed, and the modified equivalent load method that can estimate angular distortion, transverse shrinkage, longitudinal bending and longitudinal shrinkage is presented based on the FEM principle. The proposed method was verified by conducting various case studies. The results show that by applying the proposed method, the shell element-based elastic FE approach for the welding distortion analysis can be achieved with improved accuracy.

\section{Methods}

\subsection{Limitation of Conventional Equivalent Load Method}

Three inherent deformations are longitudinal shrinkage, longitudinal bending distortion, transverse shrinkage, and transverse bending distortion [17]. The equivalent loads which are used for the elastic FE welding distortion analysis using shell elements can be directly calculated from the experiment deformation measured data. According to the conventional equivalent load method (Figure 1), the relation between the equivalent load $\left(F_{T}, F_{L}, M_{T}\right.$ and $\left.M_{L}\right)$ and the measured deformation $\left(\delta_{T}, \delta_{L}, \theta_{T}\right.$ and $\left.\theta_{L}\right)$ can be expressed as follows:

$$
\begin{gathered}
F_{T}=E \cdot t \cdot\left(\frac{l_{2}}{l_{1}}\right) \cdot \delta_{T} \\
F_{L}=E \cdot t \cdot\left(\frac{l_{1}}{l_{2}}\right) \cdot \delta_{L} \\
M_{T}=\frac{E \cdot t^{3}}{12\left(1-v^{2}\right)} \cdot\left(\frac{l_{1}}{l_{2}}\right) \cdot \theta_{T} \\
M_{L}=\frac{E \cdot t^{3}}{12\left(1-v^{2}\right)} \cdot\left(\frac{l_{1}}{l_{2}}\right) \cdot \theta_{L}
\end{gathered}
$$

where $M_{L}$ is the equivalent bending moment acting parallel to welding line $(\mathrm{N} / \mathrm{mm}) ; M_{T}$ is the equivalent bending moment acting perpendicular to welding line $(\mathrm{N} / \mathrm{mm}) ; F_{L}$ is an equivalent load acting parallel to welding line $(\mathrm{N}) ; F_{T}$ is an equivalent load acting perpendicular to welding line $(\mathrm{N})$; $l_{1}$ is the element length parallel to the welding line $(\mathrm{mm})$, and $l_{2}$ is the element length perpendicular to the welding line $(\mathrm{mm})$ [17]. 


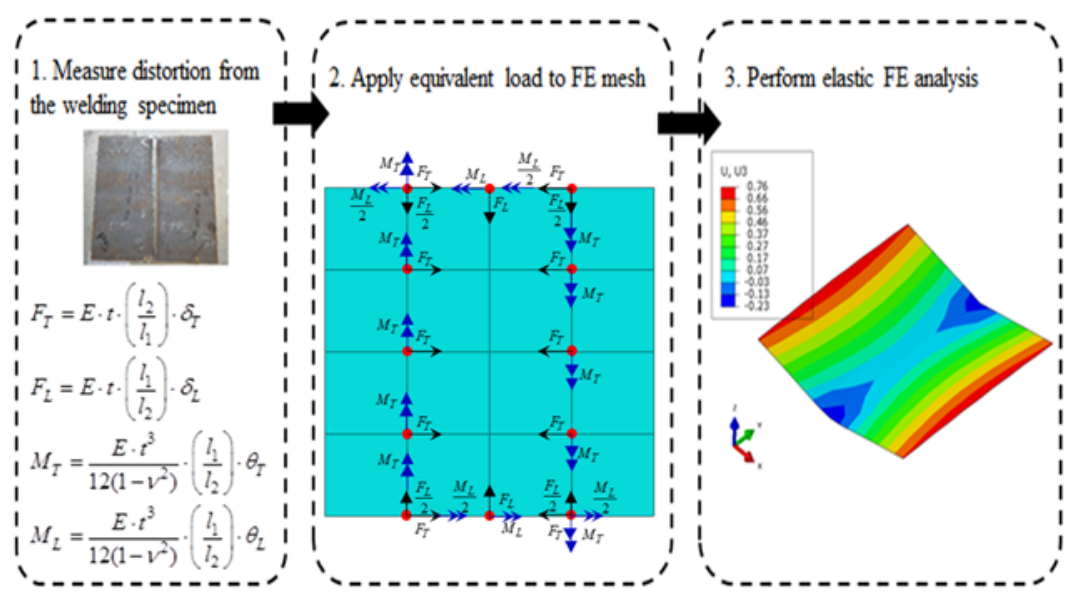

Figure 1. Analysis procedure of equivalent load method.

These calculated equivalent loads are applied as a nodal force adjacent to the weld line to simulate the desired inherent deformation. The equivalent loads are directly calculated from the measured distortion data of the welded specimen. However, the conventional equation does not consider the effect of the Poisson's ratio, so it cannot estimate the precise longitudinal inherent deformation values and transverse inherent deformation values at the same time. Here is an example. Let us assume that from the butt-welded specimen, measured inherent deformation values and the calculated equivalent loads by Equations (1)-(4) follows Tables 1 and 2.

Table 1. Inherent deformation values and conditions for the case study.

\begin{tabular}{cc}
\hline longitudinal shrinkage $\left(\delta_{L}\right)[\mathrm{mm}]$ & 0.013705 \\
Transverse Shrinkage $\left(\delta_{T}\right)[\mathrm{mm}]$ & 0.5 \\
Transverse Angular distortion $\left(\theta_{T}\right)[\mathrm{rad}]$ & 0.025 \\
Transverse deflection $[\mathrm{mm}]$ & 7.5 \\
Longitudinal Angular distortion $\left(\theta_{L}\right)[\mathrm{rad}]$ & 0.003 \\
Longitudinal deflection $[\mathrm{mm}]$ & 1.5 \\
Elastic modulus [GPa] & 200 \\
Poisson's ratio & 0.3 \\
Plate dimension $(\mathrm{L} \times \mathrm{W} \times \mathrm{t})[\mathrm{mm}]$ & $1000 \times 600 \times 10$ \\
Mesh size $\left(l_{1} \times l_{2}\right)$ & $20 \times 20$
\end{tabular}

Table 2. Equivalent loads for the case study.

\begin{tabular}{cc}
\hline Equivalent transverse bending moment $\left(M_{T}\right)[\mathrm{N} / \mathrm{mm}]$ & $457,875.5$ \\
Equivalent longitudinal bending moment $\left(M_{L}\right)[\mathrm{N} / \mathrm{mm}]$ & $54,945.1$ \\
Equivalent transverse shrinkage force $\left(F_{T}\right)[\mathrm{N}]$ & $1,000,000$ \\
Equivalent longitudinal shrinkage force $\left(F_{L}\right)[\mathrm{N}]$ & $27,410.4$ \\
\hline
\end{tabular}

All of the degree of freedom was fixed for the central node for the boundary condition of the case study. The results show that predicted longitudinal deflection value $(5.8 \mathrm{~mm})$ shows high error compared to the inherent deformation value $(1.5 \mathrm{~mm})$. Moreover, the longitudinal shrinkage value shows a different tendency (Figure 2). In-plane inherent deformation values are shrinkage values. However, simulation results show longitudinal expansion. Simulated longitudinal shrinkage values are highly affected by the longitudinal constraint so it is represented as tendon force $[18,19]$. Predicted values vary according to the FE mesh so it is recommended to use coarse FE mesh in the welding direction. However, showing the opposite tendency is not correct. 

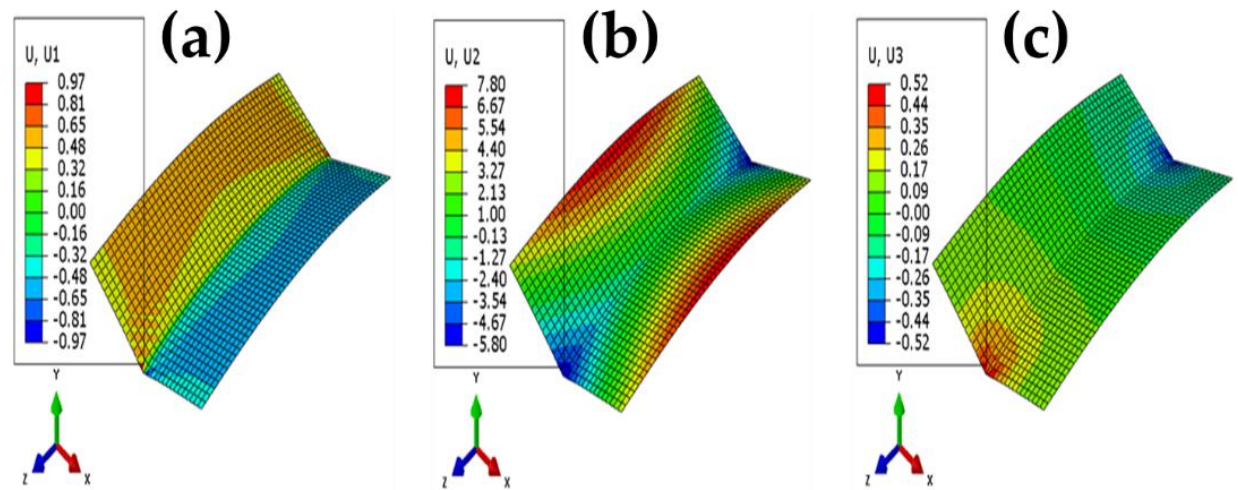

Figure 2. Result of case study including all equivalent loads: (a) X-direction displacement contour plot; (b) Y-direction displacement contour plot (c) Z-direction displacement contour plot.

Figure 3 shows the simulation results, applying equivalent load method for the case study excluding the equivalent longitudinal bending moment and equivalent longitudinal shrinkage force, (i.e., tendon force).
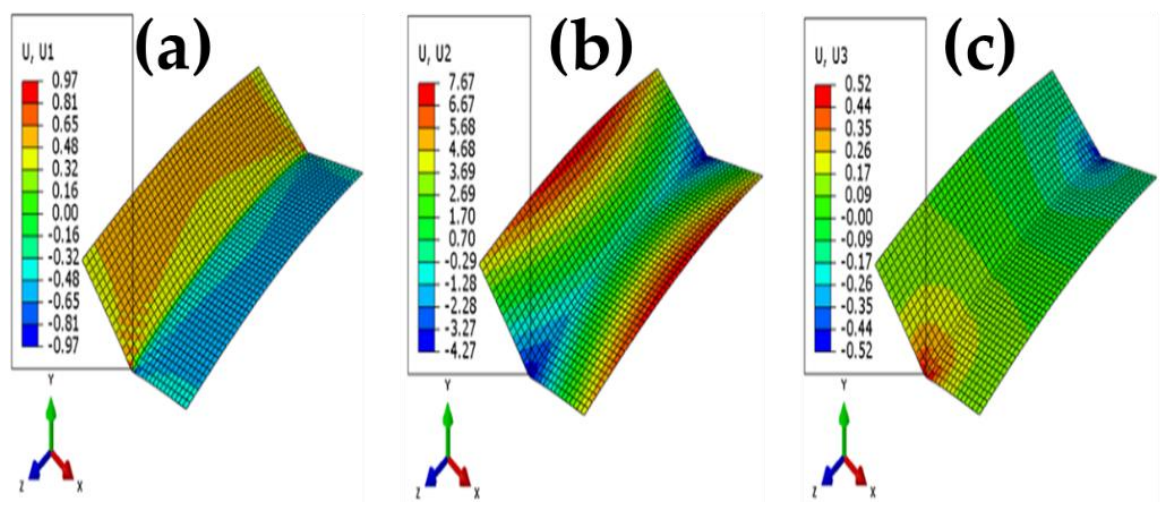

Figure 3. Results of case study excluding longitudinal equivalent loads: (a) X-direction displacement contour plot (b) Y-direction displacement contour plot (c) Z-direction displacement contour plot.

The results show the longitudinal deflection value $(4.27 \mathrm{~mm})$ and longitudinal expansion, even though equivalent longitudinal bending moment and tendon force was excluded. This is due to the Poisson's ratio effect and it should be corrected. Inherent strain theory research groups $[7,8]$ have already considered this effect when converting the inherent deformation to inherent strain. However, conventional equivalent load method does not consider these effects so the predicted longitudinal deformation values show low accuracy. Considering, the fundamental of the equivalent load method is applying the equivalent nodal force values that can simulate the pre-estimated inherent deformation values; the conventional equivalent load methods must be modified.

\subsection{Modified Equivalent Load Method}

Before describing the proposed method, we derive the modified equivalent force that generates the inherent transverse shrinkage value that excludes longitudinal deformation (Figure 4). Because of the effect of Poisson's ratio, applying nodal force along only the transverse direction generates displacements along the longitudinal direction. 

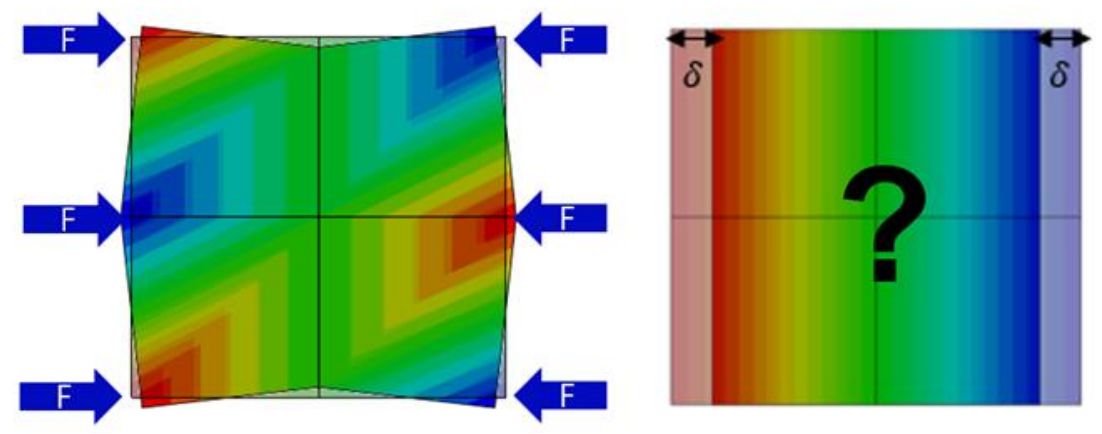

Figure 4. Displacement by equivalent force method.

Flat shell elements are considered in the proposed method, and are formulated through the assembly of 2D plane stress elements and plate elements [20]. Let us consider the plane stress element to derive a modified solution for the equivalent force method. Figure 5 shows the general four-node quadrilateral element.

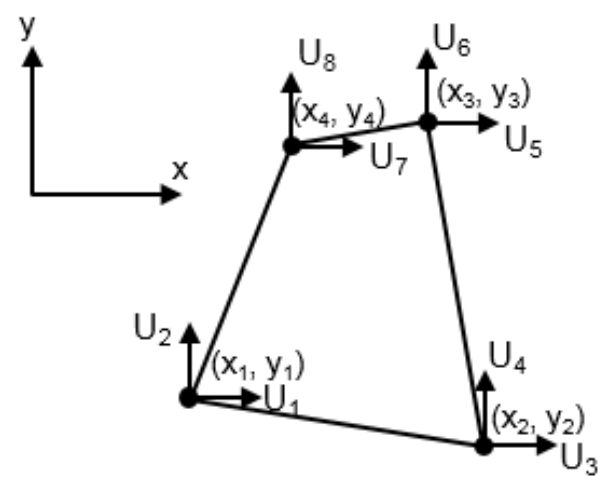

Figure 5. General four-node quadrilateral element.

For an isotropic material, the stress-strain matrix $\mathbf{D}$ can be expressed as Equation (5):

$$
\mathbf{D}=\frac{E}{1-v^{2}}\left[\begin{array}{ccc}
1 & v & 0 \\
v & 1 & 0 \\
0 & 0 & (1-v) / 2
\end{array}\right]
$$

The element stiffness matrix of 2D plane stress element $k_{m}$ is given by Equation (6):

$$
\mathbf{k}_{m}=t \int_{A} \mathbf{B}^{T} \mathbf{D B} d A
$$

The strain/displacement matrix $\mathbf{B}$ is given by Equation (7):

$$
\mathbf{B}=\left[\begin{array}{cccccccc}
\frac{\partial N_{1}}{\partial x} & 0 & \frac{\partial N_{2}}{\partial x} & 0 & \frac{\partial N_{3}}{\partial x} & 0 & \frac{\partial N_{4}}{\partial x} & 0 \\
0 & \frac{\partial N_{1}}{\partial y} & 0 & \frac{\partial N_{2}}{\partial y} & 0 & \frac{\partial N_{3}}{\partial y} & 0 & \frac{\partial N_{4}}{\partial y} \\
\frac{\partial N_{1}}{\partial y} & \frac{\partial N_{1}}{\partial x} & \frac{\partial N_{2}}{\partial y} & \frac{\partial N_{2}}{\partial x} & \frac{\partial N_{3}}{\partial y} & \frac{\partial N_{3}}{\partial x} & \frac{\partial N_{4}}{\partial y} & \frac{\partial N_{4}}{\partial x}
\end{array}\right]
$$

where $E, t, N_{i}$, and $v$ are Young's modulus, plate thickness, shape function, and Poisson's ratio, respectively. A square mesh of dimensions $L \times L$ (in $\mathrm{mm}$ ) is considered in this study. In case of the master domain of the four-node iso-parametric element shown in Figure 6, the shape functions at each node are as follows: 


$$
N_{1}=\frac{1}{4}(1-s)(1-t), N_{2}=\frac{1}{4}(1-s)(1+t), N_{3}=\frac{1}{4}(1+s)(1+t), N_{4}=\frac{1}{4}(1+s)(1-t)
$$
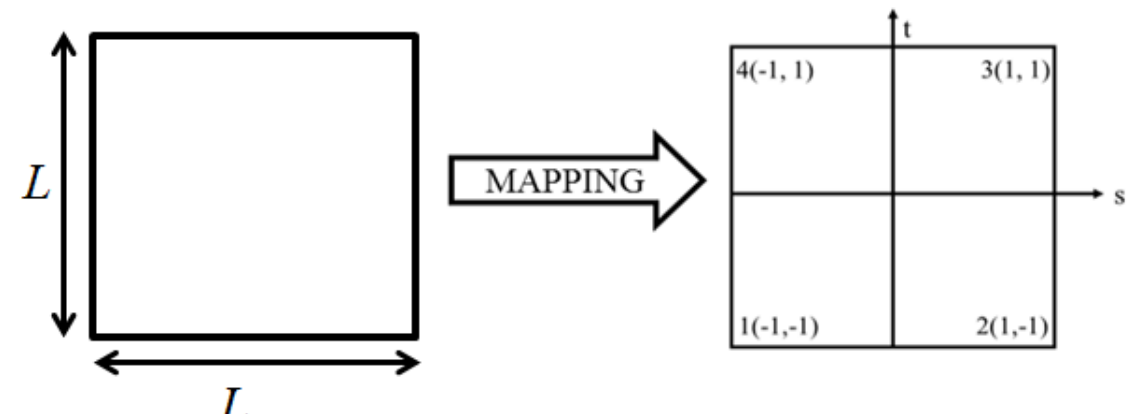

Figure 6. Master domain of the four-node iso-parametric element.

The numerically integrated 2D plane stress element stiffness matrix can be expressed as Equation (9):

$$
\mathbf{k}_{m}=t \sum_{i=1}^{N} \sum_{j=1}^{N} w_{i j}(\operatorname{det} J)_{i j} \mathbf{B}^{T} \mathbf{D} \mathbf{B}_{i j}
$$

For simplicity, one-point numerical integration is considered here, $\mathrm{N}=1$, where the weighting coefficient $w_{i j}$ is four and the point of integration is $(0,0)$ in the local coordinates $(\mathrm{s}, \mathrm{t})$. The scalar $(\operatorname{det} J)$, which is the determinant of the Jacobian matrix, becomes $L^{2} / 4$, where the Jacobian matrix can be expressed as Equation (10):

$$
\mathbf{J}=\left[\begin{array}{ll}
\frac{\partial x}{\partial s} & \frac{\partial y}{\partial s} \\
\frac{\partial x}{\partial t} & \frac{\partial y}{\partial t}
\end{array}\right]
$$

Then, the closed form of the 2D plane stress element stiffness matrix can be derived as Equation (11):

$$
\mathbf{k}_{m}=\left[\begin{array}{cccccccc}
-A & C & -C & B & A & -C & C & -B \\
C & -A & -B & C & C & A & B & -C \\
-C & -B & -A & -C & -C & B & A & C \\
B & C & -C & -A & -B & -C & C & A \\
A & -C & C & -B & -A & C & -C & B \\
-C & A & B & -C & C & -A & -B & C \\
C & B & A & C & -C & -B & -A & -C \\
-B & -C & C & A & B & C & -C & -A
\end{array}\right]
$$

Let us consider a mesh system with four square elements and nine nodes (Figure 7). Based on the derived plane stress element stiffness matrix, the system's stiffness matrix can be derived. Then, the force vector term that generates only transverse shrinkage $\left(\delta_{T}\right)$ can be derived as Equation (12):

$$
\begin{aligned}
& \mathbf{U}^{T}=\left[\begin{array}{lllllllllllllll}
\delta_{T} & 0 & 0 & 0 & -\delta_{T} & 0 & \cdot & \cdot & \cdot & \delta_{T} & 0 & 0 & 0 & -\delta_{T} & 0
\end{array}\right] \\
& \mathbf{F}^{T}=\left[\begin{array}{lllllllllll}
F_{x_{1}} & F_{y_{1}} & F_{x_{2}} & F_{y_{2}} & F_{x_{3}} & F_{y_{3}} & \cdot & \cdot & \cdot & F_{x_{9}} & F_{y_{9}}
\end{array}\right]
\end{aligned}
$$



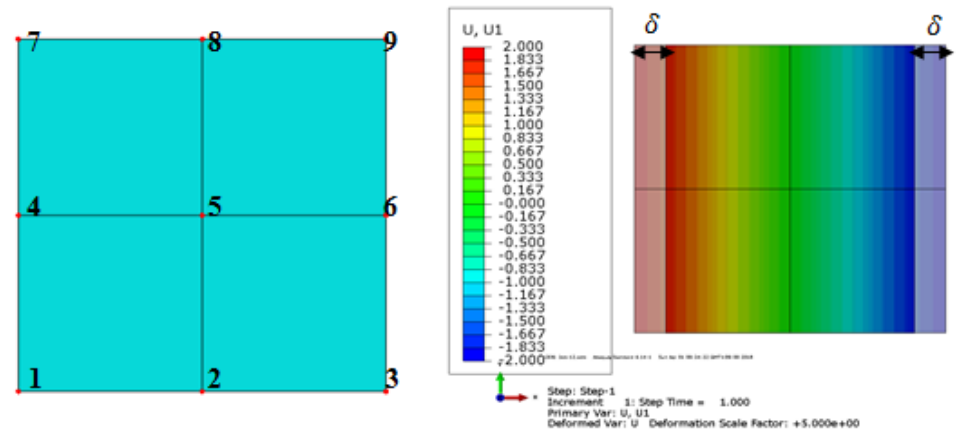

Figure 7. square elements in a 9-node mesh system.

The force vector term that generates transverse shrinkage $\left(\delta_{T}\right)$ can be derived as Equation (13). Each term represents the equivalent nodal loads used to generate only transverse shrinkage in Figure 8.

$$
F_{x_{1}}=\frac{E \delta_{T} t}{2\left(1-v^{2}\right)}, F_{x_{2}}=\frac{E \delta_{T} t}{\left(1-v^{2}\right)}, F_{y_{1}}=\frac{E v \delta_{T} t}{2\left(1-v^{2}\right)}, F_{y_{2}}=\frac{E v \delta_{T} t}{\left(1-v^{2}\right)}
$$

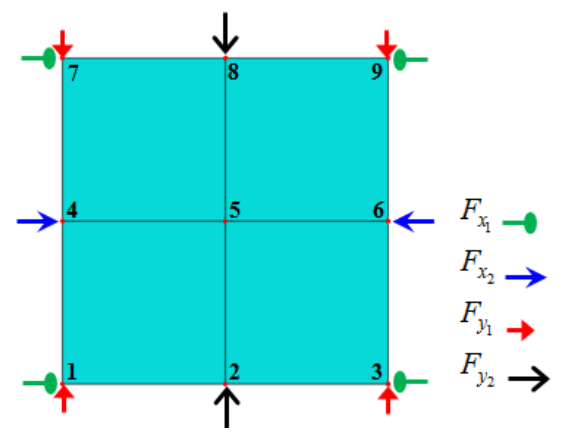

Figure 8. Modified equivalent loads needed to generate only transverse shrinkage.

The same procedure can be applied to other mesh systems with square elements. The modified solution for the equivalent force method can be derived as shown in Equation (13) and Figure 9. Due to Poisson's ratio, additional nodal force terms should be considered at the end nodes to generate only transverse shrinkage.
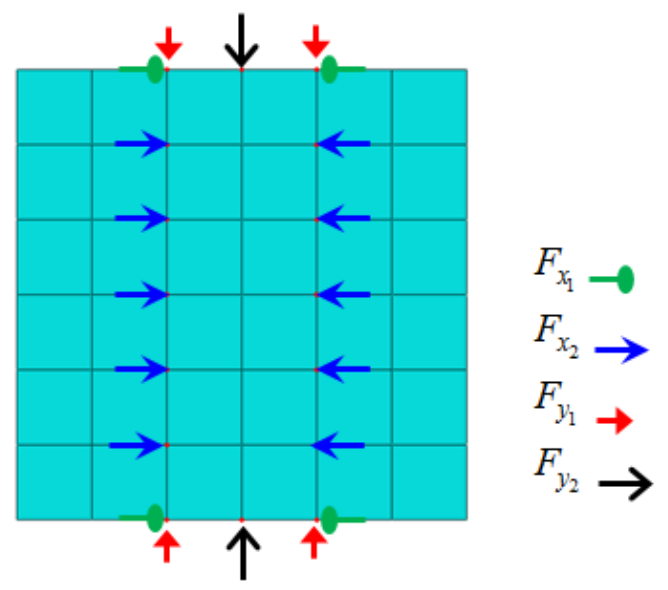

Figure 9. Modified equivalent load needed to generate pure shrinkage for the general case.

A simple case study was performed for verification. The conditions and input values are described in Table 3. 
Table 3. Conditions for the case study.

\begin{tabular}{cccc}
\hline Thickness [mm] & 10 & $F_{x_{1}}[\mathrm{~N}]$ & $1,098,901$ \\
Elastic modulus [GPa] & 200 & $F_{x_{2}}[\mathrm{~N}]$ & $2,197,802$ \\
Shrinkage [mm] & 1.0 & $F_{y_{1}}[\mathrm{~N}]$ & 329,670 \\
Poisson ratio & 0.3 & $F_{y_{2}}[\mathrm{~N}]$ & 659,340 \\
\hline
\end{tabular}

The results show that the derived equation can simulate only transverse shrinkage without incurring longitudinal shrinkage (Figure 10).

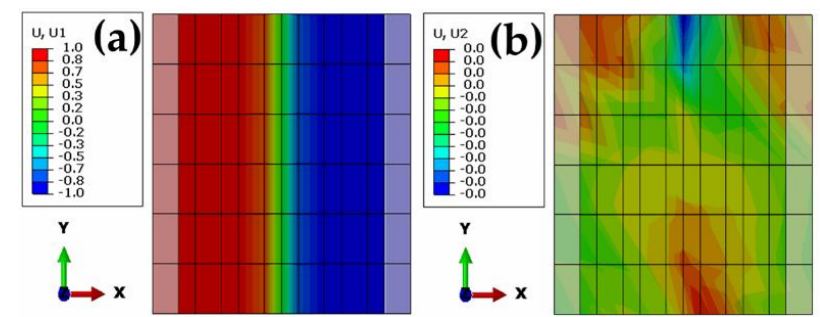

Figure 10. Results of case study: (a) X-direction displacement contour plot; (b) Y-direction displacement contour plot.

The terms of the bending moment in the global force vector can be obtained following the equations governing the plate elements. The bending strain/displacement matrix $\mathbf{B}_{b}$ is given by Equation (14):

$$
\mathbf{B}_{b}=\left(\begin{array}{cccccc}
0 & 0 & \frac{\partial N_{1}}{\partial x} \cdots & 0 & 0 & \frac{\partial N_{4}}{\partial x} \\
0 & -\frac{\partial N_{1}}{\partial y} & 0 \cdots & 0 & -\frac{\partial N_{4}}{\partial y} & 0 \\
0 & -\frac{\partial N_{1}}{\partial x} & \frac{\partial N_{1}}{\partial y} \cdots & 0 & -\frac{\partial N_{4}}{\partial x} & \frac{\partial N_{4}}{\partial y}
\end{array}\right)
$$

The element stiffness matrix of plate element $k_{b}$ is given by Equation (15):

$$
\mathbf{k}_{b}=\frac{t^{3}}{12} \int_{A} \mathbf{B}_{b}{ }^{T} \mathbf{D} \mathbf{B}_{b} d A
$$

The numerically integrated plate element stiffness matrix can be expressed as Equation (16):

$$
\mathbf{k}_{b}=\frac{t^{3}}{12} \sum_{i=1}^{N} \sum_{j=1}^{N} w_{i j}(\operatorname{det} J)_{i j} \mathbf{B}_{b}^{T} \mathbf{D} \mathbf{B}_{b i j}
$$

For simplicity, one-point numerical integration is considered here, and then the closed form of the plate element stiffness matrix can be derived as Equation (17).

$$
\begin{aligned}
& \mathbf{k}_{b}=\left[\begin{array}{cccccccccccc}
0 & 0 & 0 & 0 & 0 & 0 & 0 & 0 & 0 & 0 & 0 & 0 \\
0 & -A & -B & 0 & -B & -C & 0 & A & B & 0 & B & C \\
0 & -B & -A & 0 & C & B & 0 & B & A & 0 & -C & -B \\
0 & 0 & 0 & 0 & 0 & 0 & 0 & 0 & 0 & 0 & 0 & 0 \\
0 & -B & C & 0 & -A & B & 0 & B & -C & 0 & A & -B \\
0 & -C & B & 0 & B & -A & 0 & C & -B & 0 & -B & A \\
0 & 0 & 0 & 0 & 0 & 0 & 0 & 0 & 0 & 0 & 0 & 0 \\
0 & A & B & 0 & B & C & 0 & -A & -B & 0 & -B & -C \\
0 & B & A & 0 & -C & -B & 0 & -B & -A & 0 & C & B \\
0 & 0 & 0 & 0 & 0 & 0 & 0 & 0 & 0 & 0 & 0 & 0 \\
0 & B & -C & 0 & A & -B & 0 & -B & C & 0 & -A & B \\
0 & C & -B & 0 & -B & A & 0 & -C & B & 0 & B & -A
\end{array}\right] \\
& \text { where, } A=\frac{E t^{3}(v-3)}{96\left(v^{2}-1\right)}, B=\frac{E t^{3}}{96(v-1)}, C=\frac{E t^{3}(3 v-1)}{96\left(v^{2}-1\right)} \\
&
\end{aligned}
$$


Let us consider a mesh system with four square elements with unit size and nine nodes. Based on the derived plate element stiffness matrix, the system's stiffness matrix can be derived. Then, the force vector term that generates only transverse bending $\left(\theta_{T}\right)$ can be derived as Equation (18):

$$
\begin{aligned}
\mathbf{U}^{T} & =\left[\begin{array}{lllllllllllllll}
\theta_{T} & -\theta_{T} & 0 & 0 & 0 & 0 & \theta_{T} & \theta_{T} & 0 & \cdot & \cdot & \theta_{T} & \theta_{T} & 0
\end{array}\right] \\
\mathbf{M}^{T} & =\left[\begin{array}{lllllllllll}
0 & M_{x_{1}} & M_{y_{1}} & 0 & M_{x_{2}} & M_{y_{2}} & \cdot & \cdot & 0 & M_{x_{9}} & M_{y_{9}}
\end{array}\right]
\end{aligned}
$$

Each term represents the equivalent nodal loads used to generate pure bending in Figure 11. The same procedure can be applied to other mesh systems with square elements:

$$
M_{x_{1}}=\frac{\theta E t^{3}}{24\left(1-v^{2}\right)}, M_{x_{2}}=\frac{\theta E t^{3}}{12\left(1-v^{2}\right)}, M_{y_{1}}=\frac{\theta v E t^{3}}{24\left(1-v^{2}\right)}, M_{y_{2}}=\frac{\theta v E t^{3}}{12\left(1-v^{2}\right)}
$$

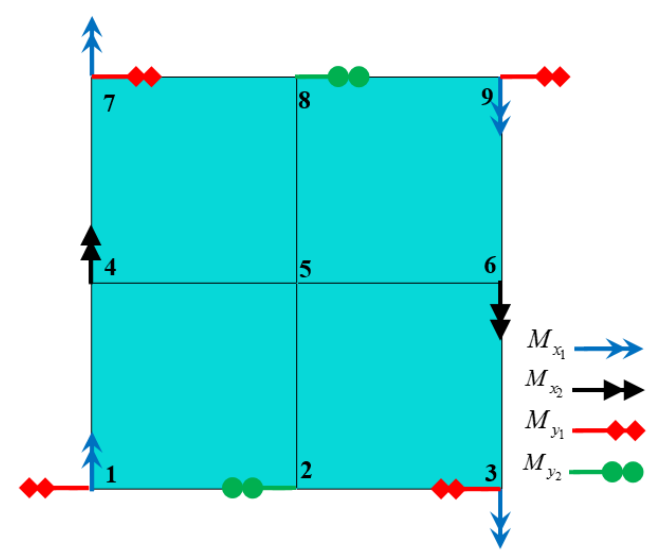

Figure 11. Modified equivalent loads needed to generate pure transverse bending.

For verification, modified equivalent load excluding longitudinal equivalent loads were applied to the previous case study. Table 4 shows the modified equivalent load terms. Figure 12 shows the result of the case study. The results show the modified terms eliminates the Poisson's ratio effect and can predict only transverse deformations.

Table 4. Modified equivalent loads for the case study.

\begin{tabular}{cc}
\hline Equivalent transverse bending moment $\left(M_{x_{1}}\right)[\mathrm{N} / \mathrm{mm}]$ & $228,937.8$ \\
Equivalent transverse bending moment $\left(M_{x_{2}}\right)[\mathrm{N} / \mathrm{mm}]$ & $457,875.5$ \\
Equivalent transverse bending moment $\left(M_{y_{1}}\right)[\mathrm{N} / \mathrm{mm}]$ & $68,681.33$ \\
Equivalent transverse bending moment $\left(M_{y_{2}}\right)[\mathrm{N} / \mathrm{mm}]$ & $137,362.7$ \\
Equivalent transverse shrinkage force $\left(F_{x_{1}}\right)[\mathrm{N}]$ & 549,451 \\
Equivalent transverse shrinkage force $\left(F_{x_{2}}\right)[\mathrm{N}]$ & $1,098,902$ \\
Equivalent transverse shrinkage force $\left(F_{y_{1}}\right)[\mathrm{N}]$ & $164,835.3$ \\
Equivalent transverse shrinkage force $\left(F_{y_{2}}\right)[\mathrm{N}]$ & $329,670.6$ \\
\hline
\end{tabular}

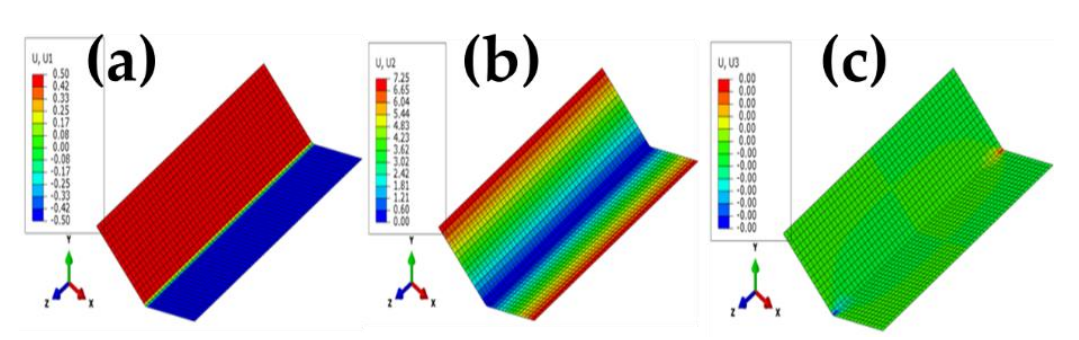

Figure 12. Result of case study applying modified equivalent load excluding longitudinal equivalent loads: (a) X-direction displacement contour plot (b) Y-direction displacement contour plot (c) Z-direction displacement contour plot. 
Figure 13 shows the result of case study applying modified equivalent load including all loads. When, applying modified equivalent load method, it is possible to predict longitudinal angular deflection and transverse deflections, at the same time, with increased accuracy (Table 5). The longitudinal shrinkage value varies with the pre-estimated inherent deformation value however since the values are highly affected by the longitudinal constraint, it is affected by the FE mesh in the welding direction [21]. When conventional method was applied, it showed the opposite tendency, however when the modified equivalent load method was applied it showed the corrected tendency.
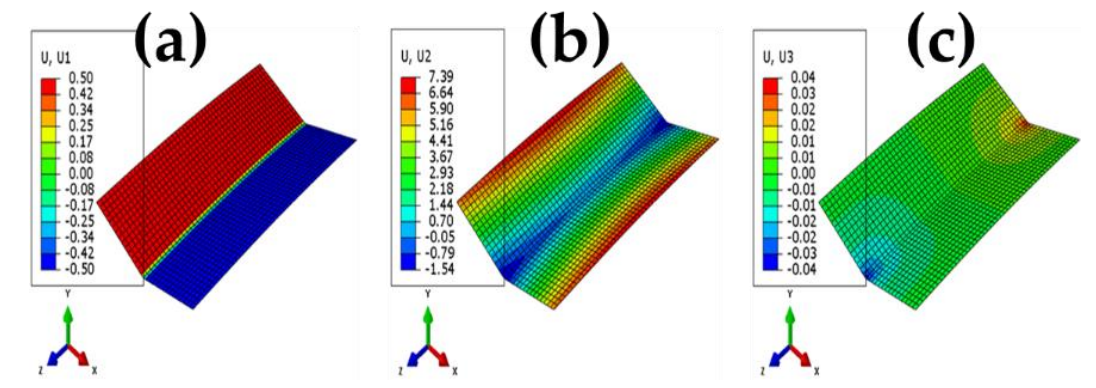

Figure 13. Result of case study applying modified equivalent load including all loads: (a) X-direction displacement contour plot; (b) Y-direction displacement contour plot; (c) Z-direction displacement contour plot.

Table 5. Result comparison between conventional equivalent load method and modified equivalent load method.

\begin{tabular}{cccc}
\hline & $\begin{array}{c}\text { Pre-estimated Inherent } \\
\text { Deformation Value }\end{array}$ & $\begin{array}{c}\text { Simulated Value } \\
\text { Applying Conventional } \\
\text { Equivalent Load Method }\end{array}$ & $\begin{array}{c}\text { Simulated Value } \\
\text { Applying Modified } \\
\text { Equivalent Load Method }\end{array}$ \\
\hline Longitudinal shrinkage $\left(\delta_{L}\right)[\mathrm{mm}]$ & 0.01370 & -0.52 & 0.04 \\
Transverse shrinkage $\left(\delta_{T}\right)[\mathrm{mm}]$ & 0.50 & 0.97 & 0.50 \\
Transverse deflection $[\mathrm{mm}]$ & 7.50 & 7.80 & 7.39 \\
Longitudinal deflection $[\mathrm{mm}]$ & 1.50 & 5.80 & 1.54 \\
\hline
\end{tabular}

\section{Case Study for the Welded Structure}

\subsection{Purpose and Assumtions}

The purpose of this case study is to verify the modified equivalent load method by performing analysis on a multi-welded structure. The main novelty of the modified equivalent load method is to eliminate the longitudinal deformations when using only the transverse inherent deformations. Therefore, only the transverse inherent deformations were used when applying the analysis methods. The longitudinal welding distortions are greatly affected by the length of the welded structure. In order to reduce these effects, a welded structure having a size of $600 \mathrm{~mm}$ (width) $\times 500 \mathrm{~mm}$ (length) was considered.

\subsection{Experiment Procedure and Input Variables Calculation}

The case study was conducted for the welded structure. The experimental model consisted of a 10-mm-thick multi-pass butt-welded joint and two fillet-welded joints. The experimental model and its result are shown in Figure 14. Table 6 shows the details of the joint and welding conditions for each welding type. 


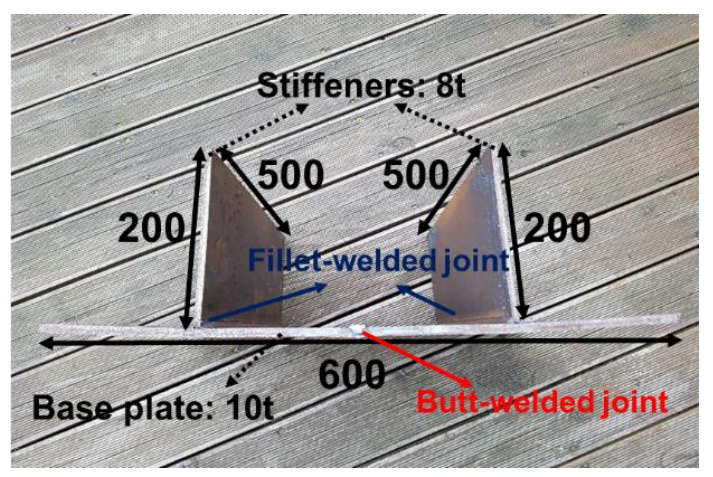

Figure 14. Experimental model and its results (dimensions in $\mathrm{mm}$ ).

Table 6. Joint details and welding conditions.

\begin{tabular}{|c|c|c|c|c|c|c|c|c|}
\hline \multirow{4}{*}{$\begin{array}{l}\text { Type } \\
\text { Butt }\end{array}$} & \multirow{4}{*}{$\begin{array}{c}\text { Material } \\
\text { AH32 }\end{array}$} & \multirow{4}{*}{$\begin{array}{c}\text { Welding } \\
\text { Process }\end{array}$} & \multirow{2}{*}{\multicolumn{2}{|c|}{ Joint Details }} & \multicolumn{4}{|c|}{ Welding Condition } \\
\hline & & & & & \multirow{2}{*}{$\begin{array}{c}\text { Pass No. } \\
1 s t\end{array}$} & \multirow{2}{*}{$\begin{array}{c}\begin{array}{c}\text { Ampere } \\
\text { (A) }\end{array} \\
150\end{array}$} & \multirow{2}{*}{$\begin{array}{c}\begin{array}{c}\text { Voltage } \\
\text { (V) }\end{array} \\
25\end{array}$} & \multirow{2}{*}{$\begin{array}{c}\begin{array}{c}\text { Speed } \\
(\mathrm{cm} / \mathrm{min})\end{array} \\
27\end{array}$} \\
\hline & & & $\begin{array}{c}\text { Groove angle } \\
\left({ }^{\circ}\right)\end{array}$ & $\begin{array}{l}\text { Root gap } \\
\text { (mm) }\end{array}$ & & & & \\
\hline & & & 40 & 4 & 2nd & 165 & 30 & 24 \\
\hline Fillet & AH32 & FCAW & $\begin{array}{r}\text { Leg leng } \\
5\end{array}$ & $\mathrm{~mm})$ & 1st & 160 & 25 & 30 \\
\hline
\end{tabular}

Inherent deformation data were collected by laser scanning device from the fillet-welded specimen and butt-welded specimen. The joint details and welding conditions for the test specimens were same with the experimental model. Figure 15 shows the results of the unit welded specimens.
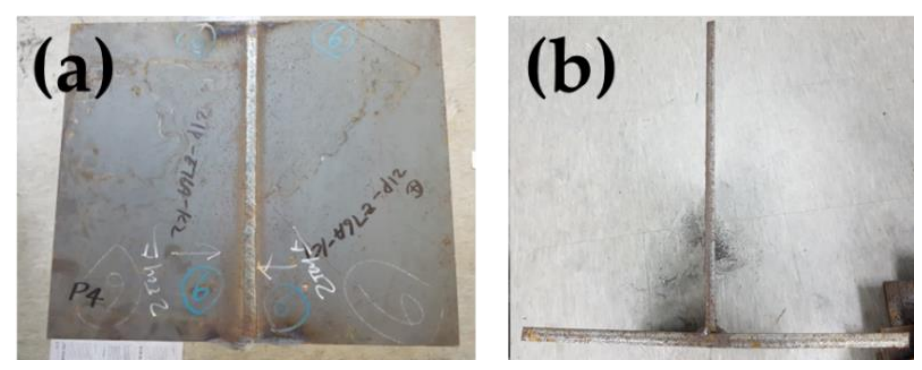

Figure 15. Results of the unit welded specimens: (a)butt-welded specimen (b) fillet-welded specimen.

Based on the measured distortion (Table 7), the input variables for the conventional equivalent load method and the modified equivalent load method were estimated as shown in Tables 8 and 9. Equivalent load for the transverse angular distortions were calculated based on the measured data at the middle of the specimen.

Table 7. Inherent deformation values and conditions for the welded structure.

\begin{tabular}{ccc}
\hline Category & Butt-Welded Joint & Fillet-Welded Joint \\
\hline Transverse Shrinkage $\left(\delta_{T}\right)[\mathrm{mm}]$ & 0.82 & 0.22 \\
\hline Transverse Angular distortion $\left(\theta_{T}\right)[\mathrm{rad}]$ & 0.032 & 0.017 \\
\hline Elastic modulus [GPa] & 200 \\
\hline Poisson's ratio & 0.3 \\
\hline
\end{tabular}


Table 8. Input variables for the conventional equivalent load method.

\begin{tabular}{ccc}
\hline Category & Butt-Welded Joint & Fillet-Welded Joint \\
\hline Equivalent transverse bending moment $\left(M_{T}\right)[\mathrm{N} / \mathrm{mm}]$ & 580,817 & 305,250 \\
\hline Equivalent transverse shrinkage force $\left(F_{T}\right)[\mathrm{N}]$ & $1,640,000$ & 440,000 \\
\hline
\end{tabular}

Table 9. Input variables for the modified equivalent load method.

\begin{tabular}{ccc}
\hline Category & Butt-Welded Joint & Fillet-Welded Joint \\
\hline Equivalent transverse bending moment $\left(M_{x_{1}}\right)[\mathrm{N} / \mathrm{mm}]$ & 290,409 & 152,625 \\
Equivalent transverse bending moment $\left(M_{x_{2}}\right)[\mathrm{N} / \mathrm{mm}]$ & 580,817 & 305,250 \\
Equivalent transverse bending moment $\left(M_{y_{1}}\right)[\mathrm{N} / \mathrm{mm}]$ & 87,123 & 45,788 \\
Equivalent transverse bending moment $\left(M_{y_{2}}\right)[\mathrm{N} / \mathrm{mm}]$ & 174,245 & 91,575 \\
Equivalent transverse shrinkage force $\left(F_{x_{1}}\right)[\mathrm{N}]$ & 901,099 & 241,758 \\
Equivalent transverse shrinkage force $\left(F_{x_{2}}\right)[\mathrm{N}]$ & $1,802,198$ & 483,516 \\
Equivalent transverse shrinkage force $\left(F_{y_{1}}\right)[\mathrm{N}]$ & 270,330 & 72,527 \\
Equivalent transverse shrinkage force $\left(F_{y_{2}}\right)[\mathrm{N}]$ & 540,659 & 145,055 \\
\hline
\end{tabular}

Similarly, the measurement of the experimental model was also performed through a laser scanning device. The bottom surface was scanned for the experimental model. After acquiring point cloud data, data alignment was performed, and coordinate values of specific points were extracted to calculate the overall out-of-plane distortion value. Figure 16 describes the workflow of the out-of-plane distortion measurement. Measured data of the experimental model are given in Table 10. The coordinate of center location is $(300,250)$ in the $\mathrm{XY}$ plane for the measured data.
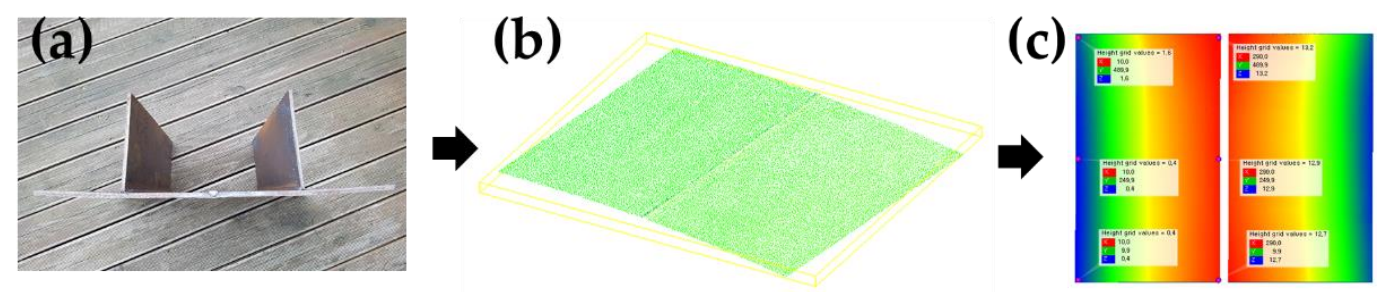

Figure 16. Workflow of the out-of-plane distortion measurement: (a) Experimental results; (b) point cloud data acquisition by laser scanning; (c) point cloud data alignment.

Table 10. Measured data of the experimental model.

\begin{tabular}{cccc}
\hline Point NO. & $\mathbf{X}$ (Width Direction) $[\mathbf{m m}]$ & $\mathbf{Y}$ (Length Direction) $[\mathbf{m m}]$ & $\mathbf{Z}$ (Out-of-Plane Direction) [mm] \\
\hline 1 & 10 & 10 & 0.4 \\
\hline 2 & 10 & 250 & 0.4 \\
\hline 3 & 10 & 490 & 1.6 \\
\hline 4 & 290 & 10 & 12.7 \\
\hline 5 & 290 & 250 & 12.9 \\
\hline 6 & 290 & 490 & 13.2 \\
\hline 7 & 310 & 10 & 13.1 \\
\hline 8 & 310 & 250 & 12.4 \\
\hline 9 & 310 & 490 & 13.1 \\
\hline 10 & 590 & 10 & 1.9 \\
\hline 11 & 590 & 250 & 1 \\
\hline 12 & 590 & 490 & 1.9 \\
\hline
\end{tabular}




\subsection{Welding Distortion Analysis and Comparison of Various Methods}

For the welding distortion analysis, common FE code ABAQUS was used. Shell elements S4R, which are 4-node doubly curved thin shell, reduced integration, were applied for the analysis. The mesh sizes for the analysis were set to $50 \mathrm{~mm}$ and $25 \mathrm{~mm}$. Every element's aspect ratio was equal to 1 . All of the degrees of freedom were fixed for the central node for the boundary condition of the analysis model. Figure 17 shows the displacement contour plot of various methods.

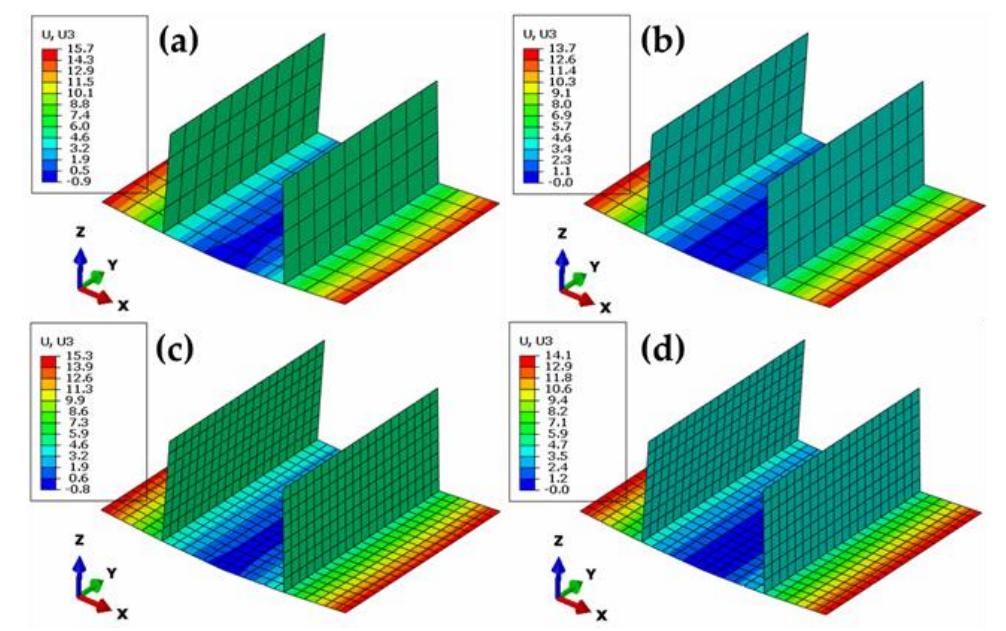

Figure 17. Displacement contour plot of various methods: (a) conventional equivalent load method (mesh size: $50 \mathrm{~mm}$ ); (b) modified equivalent load method (mesh size: $50 \mathrm{~mm}$ ); (c) conventional equivalent load method (mesh size: $25 \mathrm{~mm}$ ); (d) modified equivalent load method (mesh size: $25 \mathrm{~mm}$ ).

Finally, Figure 18 presents a comparison between the conventional equivalent load method, modified equivalent load method and the experimental result. The amount of transverse angular distortions along the outer line in the longitudinal direction of the welded structure are plotted. Firstly, the experiment results show the difference in the distortion value according to the measured location is relatively small. This means that the longitudinal angular distortion is small. The longitudinal angular distortion pattern in the experiment result shows a 'convex shape' which means that plate surface is curved outward. However, the result of the conventional equivalent load method shows a 'concave shape' which means that the plate surface is curved inward. This means that the conventional load method has a numerical error when it comes to estimating the longitudinal distortions. In contrast, the modified equivalent load method shows constant distortion value along the measured location.

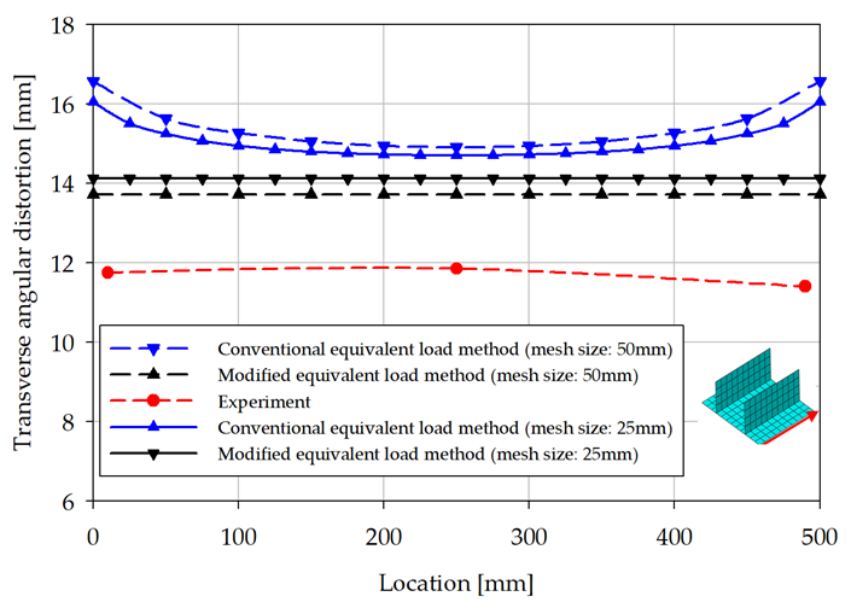

Figure 18. Comparison of angular deformations yielded by each method with experimental result. 
The equivalent load method is a methodology that predicts the distortion of the welded structure using the inherent deformation data of the unit specimens. This means that when only the transverse inherent deformations are considered, the welded structure should also show only the transverse distortions. From that point of view, it is obvious that the modified equivalent load method has improved accuracy. Moreover, the modified equivalent load method is more effective than the conventional equivalent load method, as the result is closest to the experimental data.

\section{Summary}

In this study, the problem of the conventional equivalent load method for welding distortion analysis was analyzed by means of a case study. Modified equivalent load that generates only transverse inherent deformation terms was derived based on the FEM principle. The modified equivalent load method was verified by comparing with the results of a conventional equivalent load method and pre-estimated inherent deformation value. The modified equivalent load method can predict the overall angular deformation of the welded structure with improved accuracy compared to the conventional method, even with using the identical inherent deformation data. The results show that by applying the modified equivalent load method, the accuracy of the simulation can be improved.

The limitation of this work is that the proposed method yields a difference of approximately $10 \%$ from the experiment results of the multi-welded structure. This is because when applying an elastic FE approach, such as the equivalent load method, it is difficult to precisely reflect the complicated effect of residual stress that occurs in the multi-welded structure. In the future, we will consider the residual stress effect in the equivalent load method in order to improve the accuracy of the simulation.

Author Contributions: Conceptualization, J.L. and H.C.; methodology, J.L; investigation, J.L.; resources, H.C.; data curation, J.L.; writing-original draft preparation, J.L.; writing—review and editing, J.L. and H.C.; visualization, J.L.; supervision, H.C. All authors have read and agreed to the published version of the manuscript.

Funding: This research was supported by the research fund of Chonnam National University \& Chungnam National University.

Acknowledgments: This article is an addition based on part of the first author's doctoral dissertation from University.

Conflicts of Interest: The authors declare no conflict of interest.

\section{References}

1. Goldak, J.; Akhlaghi, M. Computational Welding Mechanics; Springer: New York, NY, USA, 2005.

2. Lindgren, L.E. Numerical modelling of welding. Comput. Methods Appl. Mech. Eng. 2006, 195, 6710-6736. [CrossRef]

3. Dutta, D.; Alimardani, M.; Toyserkani, E. The Theory of moving sources of heat and its application to metal treatments. J. Mater. Process. Technol. 2012. [CrossRef]

4. Ha, Y.S. Development of thermal distortion analysis method on large shell structure using inherent strain as boundary condition. J. Soc. Nav. Archit. Korea 2008, 45, 93-100. [CrossRef]

5. Wang, J.; Rashed, S.; Murakawa, H.; Luo, Y. Numerical prediction and mitigation of out-of-plane welding distortion in ship panel structure by elastic FE analysis. Mar. Struct. 2013, 34, 135-155. [CrossRef]

6. Ueda, Y.; Kim, Y.C.; Yuan, M.G. A predicting method of residual stress using source of residual stress (report I): Characteristics of inherent strain (source of residual stress). Trans. Jpn. Weld. Res. Inst. 1989, 18, 135-141.

7. Luo, Y.; Murakawa, H.; Ueda, Y. Prediction of welding deformation and residual stress by elastic FEM based on inherent strain (2nd report)—Deformation and residual stress under multiple thermal cycles. J. Soc. Nav. Archit. Jpn. 1997, 182, 783-793. [CrossRef]

8. Luo, Y.; Murakawa, H.; Ueda, Y. Prediction of welding deformation and residual stress by elastic FEM based on inherent strain (3rd report)—deformation and residual stress in narrow gap welding. J. Soc. Nav. Archit. Jpn. 1998, 183, 323-333. [CrossRef]

9. Lee, C.H. Prediction of Welding Deformation of Ship Hull Panel Blocks Using Equivalent Loading Method Based on Inherent Strain. Ph. D. Thesis, Seoul National University, Seoul, Korea, 2002. 
10. Jang, C.D. Welding Distortion Analysis of Hull Blocks Using Equivalent Load Method Based on Inherent Strain; Technical Report SSC-453; Ship Structure Committee: Washington, DC, USA, 2007.

11. Park, J.U.; An, G. Prediction of the welding distortion of large steel structure with mechanical restraint using equivalent load methods. Int. J. Nav. Archit. Ocean Eng. 2017, 9, 315-325. [CrossRef]

12. Park, J.-U.; An, G.B. Effect of welding sequence to minimize fillet welding distortion in a ship's small component fabrication using joint rigidity method. Proc. Inst. Mech. Eng. Part B J. Eng. Manuf. 2016, 230, 643-653. [CrossRef]

13. Lee, J.M.; Seo, H.D.; Chung, H. Efficient welding distortion analysis method for large welded structures. J. Mater. Process. Technol. 2018, 256, 36-50. [CrossRef]

14. Wu, C.; Kim, J.W. Review on Mitigation of Welding-Induced Distortion Based on FEM Analysis. J. Weld. Join. 2020, 38, 56-66. [CrossRef]

15. Woo, D.; Kitamura, M. Numerical Prediction of Welding Distortion Considering Gravity Force on General Ship Grillage Structure by Elastic Finite Element Method Using Inherent Strain. J. Mar. Sci. Eng. 2020, 8, 454. [CrossRef]

16. Shin, S.-B.; Lee, D.-J.; Youn, J.-G. A Structural Design Approach for Controlling Welding Distortion at the Upper Deck of a Hull Structure in the Erection Stage. Weld. World 2012, 56, 51-63. [CrossRef]

17. Park, J.U.; Lee, H.W.; Bang, H.S. Effects of mechanical constraints on angular distortion of welding joints. Sci. Technol. Weld. Join. 2002, 7, 232-239. [CrossRef]

18. Wang, J.; Yin, X.; Murakawa, H. Experimental and computational analysis of residual buckling distortion of bead-on-plate welded joint. J. Mater. Process. Technol. 2013, 213, 1447-1458. [CrossRef]

19. Wang, J.; Rashed, S.; Murakawa, H. Mechanism investigation of welding induced buckling using inherent deformation method. Thin Walled Struct. 2014, 80, 103-119. [CrossRef]

20. Nguyen-Van, H.; Mai-Duy, N.; Tran-Cong, T. An improved quadrilateral flat element with drilling degrees of freedom for shell structural analysis. Comput. Model. Eng. Sci. 2009, 49, 81-110. [CrossRef]

21. Murakawa, H.; Deng, D.; Ma, N. Concept of inherent strain, inherent stress and inherent deformation and inherent force for prediction of welding distortion and residual stress. Trans. JWRI 2010, 39, 103-105.

(C) 2020 by the authors. Licensee MDPI, Basel, Switzerland. This article is an open access article distributed under the terms and conditions of the Creative Commons Attribution (CC BY) license (http://creativecommons.org/licenses/by/4.0/). 